\title{
Dinner and a Show: The role of male copulatory courtship song and female blood-feeding in the reproductive success of Lutzomyia longipalpis from Lapinha, Brazil.
}

Felipe M. Vigoder ${ }^{1}$, Alejandra S. Araki ${ }^{2}$, Antonio Bernardo de Carvalho ${ }^{1}$, Reginaldo P. Brazil $^{3}$, Michael G. Ritchie ${ }^{4}$

1 Departamento de Genética, Universidade Federal do Rio de Janeiro, Caixa Postal 68011, 21941-971, Rio de Janeiro, Brazil.

${ }^{2}$ Laboratório de Biologia Molecular de Insetos, Instituto Oswaldo Cruz, FIOCRUZ, Rio de Janeiro, Brazil.

${ }^{3}$ Laboratório de Bioquímica e Fisiologia de Insetos, Instituto Oswaldo Cruz, FIOCRUZ, Rio de Janeiro, Brazil.

${ }^{4}$ Centre for Biological Diversity, School of Biology, University of St Andrews, Fife, KY169TH, UK.

Key words: sand flies; copulatory courtship; copulation song; Lutzomyia longipalpis; species complex; sexual behaviour; blood-feeding

Corresponding author:

Felipe de Mello Vigoder

Laboratório de Genômica Evolutiva

Departamento de Genética

Universidade Federal do Rio de Janeiro

21941-971

Rio de Janeiro, Brazil;

e-mail: fvigoder@gmail.com 


\section{Abstract:}

Lutzomyia longipalpis is the main vector of visceral Leishmaniasis in the Americas and is composed of a species complex. Males of this sand-fly produce acoustic signals during copulation and different patterns are observed among Brazilian populations. Such acoustic signals are commonly involved in species recognition. However, since the song is only produced during copulation it is not clear how it affects mating success or contributes to sexual isolation. Another aspect that may affect reproductive success is the presence of food. Since hematophagy is such an important aspect of $L$. longipalpis biology, we wanted to test if blood-feeding can influence the reproductive behaviour of this insect. We performed crossing experiments removing males' wings (silencing them) and playing back either the homo-specific or the heterospecific song to either unfed or blood-fed females. Our results showed that both songs and blood-feeding affect insemination success, but not the frequency of copulation. In trials where females were not blood-fed song clearly affected insemination; males with wings, and males with homo-specific song playback had a higher insemination success than wingless males (no song) and trials with hetero-specific song. Blood-feeding females prior to the trials increased insemination in all groups including the control group which suggests that mating happens simultaneously with, or immediately after, the blood meal. Blood-fed females also seemed to discriminate less against the wrong song or the lack of song (wingless) one day after feeding, however trials with the correct song still had higher insemination rates. Altogether, our results show that both the male copulatory courtship songs and female blood-feeding are important for 
reproductive success and as such are important components of the sexual behaviour of $L$. longipalpis. 


\section{Introduction:}

Sexual selection can be a major driver of speciation. Changes in sexual behaviour can cause reproductive isolation thereby preventing gene flow between populations, an essential aspect of speciation (Ritchie, 2007; Kraaijeveld et al., 2011; Maan and Seehausen, 2011; Servedio and Boughman, 2017). Identifying components of mating behaviour that affect reproductive success is important to understand mating success, gene flow and the evolutionary divergence of populations.

Chemical and acoustic signals are commonly used in courtship behaviour in insects (Johansson and Jones, 2007; Hunt and Sakaluk, 2014; Tishechkin and Vedenina, 2016). Males of the sand-fly Lutzomyia longipalpis produce both types of signals (Hamilton et al., 1994; Hamilton et al., 1996a; Hamilton et al., 1996b; Brazil and Hamilton, 2002; de Souza et al., 2002; Souza et al., 2004; Watts et al., 2005; Casanova et al., 2006; Brazil et al., 2009; Vigoder et al., 2013; Vigoder et al., 2015; Spiegel et al., 2016). This insect is the main vector of Leishmaniasis in the Americas (Rangel and Shaw, 2018) and is actually a species complex composed of several cryptic species (without obvious morphological differences) in Brazil (reviewed in (Souza et al., 2017). The putative species have been identified based on differences in the male pheromones, copulatory courtship song and genetic differences (Ward et al., 1986; Ward et al., 1988; Ward and Morton, 1991; Bauzer et al., 2002a; Bauzer et al., 2002b; Bottecchia et al., 2004; Souza et al., 2004; Watts et al., 2005; Bauzer et al., 2007; Lins et al., 2008; Araki et al., 2009; Vigoder et al., 2010; Araki et al., 2013; Vigoder et al., 2015; Souza et al., 2017; Ready et al., 2018). 
The male volatile pheromones are produced by glands located in pale spots in the abdomen (Hamilton, et al. 1994; Hamilton and Ward 1991). Four chemotypes have been found in Brazilian populations (Hamilton et al., 2005; Watts et al., 2005) and both females and males are attracted to the pheromone (Spiegel et al., 2005b). The populations tested so far show discrimination between homo-specific and hetero-specific pheromones with a clear preference for the homo-specific type (Ward and Morton, 1991).

Seven different song patterns have been recorded from Brazilian populations, which can be divided into three types (Araki et al., 2009; Vigoder et al., 2013; Vigoder et al., 2015). The songs are produced by males beating their wings during copulation (after the males clasps the females) (de Souza et al., 2002). Of the three song types, the "Pulse-type" is the more variable with five different patterns being identified so far. The patterns were named P1, P2, P3, $\mathrm{P} 4$ and P5 and present both qualitative and quantitative differences that are thought to represent five distinct species (Araki et al., 2009; Vigoder et al., 2015).

The "Burst-type" song is the most common and is found in males from sixteen different Brazilian populations. The pattern is similar among them, with all populations thought to comprise a single species. A last type called "Mixtype" was found in only one population and in spite of the fact that it has characteristics from the other two types, starting more like a Pulse-type and ending with a pattern similar to the Burst-type, this type is quite distinct, likely representing yet another species (Vigoder et al., 2013; Vigoder et al., 2015). Hence the complex seems to comprise at least 7 species, 5 Pulse-type, plus 
one Burst-type and one Mix-type. A table with all populations studied and their respective song type is presented in Supplemental Table 1.

Acoustic signals produced during mating behaviour are often involved in species recognition (Hoy et al., 1988; Hoikkala et al., 1998; DesutterGrandcolas and Robillard, 2004; Ritchie et al., 2005; Huttunen et al., 2008). The variation observed in the L. longipalpis male copulatory courtship song pattern, together with the fact that patterns are consistent within populations, suggests that the song of L. longipalpis also plays a role in mating success (Souza et al., 2004; Vigoder et al., 2015). However, the fact that the song is produced only after the copulation has already started is unusual. Other studies of 'copulatory' song have suggested this might extend the duration of copulation and be favoured in sperm competition (Edvardsson and Arnqvist, 2000; Eberhard, 2001; Peretti and Eberhard, 2010; Li et al., 2012; Chen et al., 2019).

The best evidence to try to understand the role of song comes from crossing experiments between some Brazilian population with different types of song. First (Ward et al., 1988) and later (Souza et al., 2008) observed that in some inter-population crossings there was a considerable rate of crosspopulation copulation but the mating was unsuccessful as there was no insemination (Ward et al., 1988) or no larval eclosion (Souza et al., 2008). These results suggest the existence of a signal, after copulation has started, that affects reproductive success. The male copulatory song is a prime candidate for such a signal.

The presence of food can also influence mating success. In many insects, males provide nutritious nuptial gifts as part of the courtship display (Lewis et al., 2014). In Drosophila, mating frequency increases in the presence 
of food (Grosjean et al., 2011; Gorter et al., 2016). In hematophagous insects, blood feeding is a major aspect of their biology, since in most species females need the blood the develop the eggs (Clements, 2000; Lehane, 2005; Brazil and Brazil, 2018), however it is seldom considered how feeding affects reproductive success. Females blood-feed after mating in mosquitos (Takken et al., 2006; Dieng et al., 2019) and it is not clear if this is also the case in sandflies.

In the present study we investigate the role of both male copulatory song and blood-feeding by females in the reproductive success of $L$. longipalpis. We show that both aspects affect insemination and are therefore important aspects of the mating system.

\section{Material and Methods:}

\subsection{Rearing:}

Sand-flies were collected in Lapinha, MG, Brazil (19³3’S 43ํ5’'W) (license number SISBIO No 32669-4). Lapinha males produce a Pulse-type song and have 1 pair of abdominal spots.

Field caught females were pooled into groups of approximately 40 in plastic containers measuring $10 \mathrm{~cm}$ in diameter and $8 \mathrm{~cm}$ in height for oviposition. Larvae were fed in a mix of dirt and dry rabbit feces (Rangel et al., 1985) and maintained and monitored as described in Souza et al. $(1995,1999)$. Once emerged, adults were put in net cages $(20 \mathrm{~cm} \times 20 \mathrm{~cm} \times 20 \mathrm{~cm})$ and females were blood-fed on an anaesthetized hamster (Ceua P-19/11-6). All flies were maintained at $25 \pm 1^{\circ} \mathrm{C}$ and humidity close to saturation at a $12 \mathrm{~h}-12 \mathrm{~h}$ lightdark cycle. 
For the experiments, pupae were separated and imagos sexed after they emerged to guarantee virginity. Only F1 and F2 individuals from 3 to 6 days old were used in experiments.

\subsection{Song synthesis:}

Song synthesis was made using the 'Signal' system (Electronic Design) with an $\mathrm{A} / \mathrm{D}$ rate of $4 \mathrm{kHz}$. Since we only used males from Lapinha population for the experiments we used the Pulse-type song for the homo-specific group and the Burst-type song for the hetero-specific group. The Pulse-type song produced has an inter-pulse interval (IPI) of 57.3 milliseconds, a frequency of $284 \mathrm{~Hz}$ and a total length of 3.3 seconds which are the mean values found by Souza et al. (2004) for the Lapinha population (Supplemental Material 1).

An important characteristic of Lapinha song is that it consists mainly of pulses of about 1.5 cycles per pulses and some polycyclic pulses of about 6 cycles per pulse (Souza et al., 2004). The final artificial song features both types of pulses in the same proportion as observed in the male songs (Figure $1 \mathrm{~A}$ and 1B; Supplemental Material 2).

The Burst-type song was synthesized based on the averages obtained for the Pancas population according to Araki et al. (2009). This population has a normal Burst-type song with an IPI of 224.6 ms and frequency of $291.5 \mathrm{~Hz}$ lasting for $2.58 \mathrm{~s}$ (Supplemental Material 3). The artificial song is consistent with the wild Burst-type featuring both the head and tail characteristic of this type of song (Figure 1C) (Souza et al., 2004; Araki et al., 2009; Vigoder et al., 2015) (Supplemental Material 4). 
Songs were played back from a laptop computer to a Bass Amplifier Block 20 series (Onerr) in a continuous loop with a 1 second interval between repetitions from the start of the trial. Sound pressure was $80 \mathrm{~dB}$ within the mating chamber, monitored with a 'Realistic' sound level meter (33-2050 on 'fast' setting).

\subsection{Playback set-up:}

Sand-flies were divided into 4 groups to test the effects of song on the frequency of copulation and insemination. In the first group, a normal male and a female were used as control without any song being played (winged control). In the other 3 groups males had their wings remove with forceps under cold anaesthesia 1 day prior to the experiment. One of the groups had a wingless male without song (wingless control), the other a wingless male while a homospecific Pulse-type song was played (wingless homo-specific) and the last one a wingless male with hetero-specific Burst-type song (wingless hetero-specific).

In all 4 groups a couple were put in a transparent plastic cylinder arena (mating chamber) $(2.5 \times 1 \times 0.5 \mathrm{~cm})$ closed by a thin nylon fabric at the top and bottom. Time to copulation (latency) and copulation duration were measured during trials where copulation occurred. A total of 6 couples were observed simultaneously. After mating the couple were separated and the female isolated for dissection in order to check for insemination (below). If no mating was observed in 30 min the couple were removed and a new trial with a new set of couples would begin. Individuals were used only once in a trial regardless of the outcome. Each group was tested at a different random order each day. All trials were performed at $25 \pm 1^{\circ} \mathrm{C}$ and only one copulation was allowed. The day after 
copulation, female spermathecae were dissected in saline solution and observed under a contrast microscope to detect the presence of spermatozoids. If any were observed the female was considered inseminated.

The same experimental set-up was repeated using blood-fed females, 1 day after feeding. In summary, the experimental design had 2 overall groups comparing blood-fed females and not blood-fed females (henceforth called unfed females) each sub-divided into 4 conditions: a) winged males without playback; b) wingless males without playback; c) wingless males with homospecific song; d) wingless males with hetero-specific song.

\subsection{Statistical analysis:}

The table with experiment data is available at https://github.com/fvigoder/ Playback-paper.

All statistical analysis was performed in $\mathrm{R}$ using the car and multcomp packages to perform the general linear model. The four groups in fed treatment and unfed treatment were separated in the analysis in order to test the effect of song by itself (unfed treatment) and the overall effect of blood-feeding when comparing both treatments. Groups were tested for differences in copulation and insemination separately. Latency and copulation duration (Duration) were also included in the model to test for their effects on insemination rates.

The code used for the statistical analysis is presented on Supplemental Material 5. 


\section{Results:}

A total of 651 couples were tested across all groups. Table 1 shows all results and Figure 2 summarizes the insemination success for all 8 groups.

Starting with trials where the females were unfed, we observed that control winged males copulated $58 \%$ of the time. Out of these trials where copulation was observed, $43.1 \%$ of the females were inseminated (Table 1). Usually, both latency to copulation and duration of copulation were shorter when copulation was successful (where females were inseminated) with an average of $\sim 303 \mathrm{~s}$ and $\sim 106 \mathrm{~s}$ respectively when compared to copulation where females were not inseminated $\sim 558 \mathrm{~s}$ and $\sim 621 \mathrm{~s}$.

Removing male wings drastically reduced insemination rate to $0 \%$ even though the decline in the percentage of copulations was not substantial: $52 \%$ against 58\% from the control (Table1). When homo-specific song (Pulse-type) was played back to couples there was an increase in insemination rate to $28.6 \%$ which was much greater than when the hetero-specific song (Burst-type) was played (only $4.3 \%$ ). 
Table 1: Summary of the results across all trials. The upper half shows the 4 trials where females were not blood-fed while the bottom half contains trials where females were blood-fed. The conditions are: Winged - winged male / no playback; Wingless - wingless male / no playback; Homo-specific - wingless male / homo-specific song playback, Hetero-specific - wingless male / hetero-specific song playback.

\begin{tabular}{|c|c|c|c|c|c|c|c|c|c|c|}
\hline & \multirow{3}{*}{$\begin{array}{c}\text { Blood- } \\
\text { Fed }\end{array}$} & & & & \\
\hline & & & & & & & \multicolumn{2}{|c|}{ Latency } & \multicolumn{2}{|c|}{ Duration } \\
\hline & & $\underset{\text { (trials) }}{\mathbf{N}}$ & Copulation & $\begin{array}{c}\text { Copulation } \\
(\%)\end{array}$ & Insemination & $\begin{array}{c}\text { Insemination } \\
(\%)\end{array}$ & $\begin{array}{l}\text { Insemination } \\
\text { (s) }\end{array}$ & $\begin{array}{c}\text { no } \\
\text { Insemination } \\
(\mathbf{s})\end{array}$ & $\begin{array}{c}\text { Insemination } \\
\text { (s) }\end{array}$ & $\begin{array}{c}\text { no } \\
\text { Insemination } \\
(\mathbf{s})\end{array}$ \\
\hline Winged & No & 112 & 65 & $58.0 \%$ & 28 & $43.1 \%$ & $\begin{array}{r}303.04 \\
( \pm 10.42) \\
\end{array}$ & $\begin{array}{r}558.00 \\
( \pm 14.22) \\
\end{array}$ & $\begin{array}{l}106.46 \\
( \pm 0.25) \\
\end{array}$ & $\begin{array}{r}621.32 \\
( \pm 1.70) \\
\end{array}$ \\
\hline Wingless & No & 100 & 52 & $52.0 \%$ & 0 & $0.0 \%$ & - & $\begin{array}{l}516.08 \\
( \pm 8.82) \\
\end{array}$ & - & $\begin{array}{l}298.81 \\
( \pm 1.01) \\
\end{array}$ \\
\hline Homo-specific & No & 104 & 56 & $53.8 \%$ & 16 & $28.6 \%$ & $\begin{array}{r}336.75 \\
( \pm 25.70) \\
\end{array}$ & $\begin{array}{c}483.53 \\
( \pm 12.47) \\
\end{array}$ & $\begin{array}{l}143.00 \\
( \pm 0.54) \\
\end{array}$ & $\begin{array}{l}185.80 \\
( \pm 0.62) \\
\end{array}$ \\
\hline Hetero-specific & No & 99 & 46 & $46.5 \%$ & 2 & $4.3 \%$ & $\begin{array}{c}946.50 \\
( \pm 980.76) \\
\end{array}$ & $\begin{array}{r}509.57 \\
( \pm 10.25)\end{array}$ & $\begin{array}{c}54.50 \\
( \pm 0.07)\end{array}$ & $\begin{array}{l}202.18 \\
( \pm 0.69)\end{array}$ \\
\hline Winged & Yes & 57 & 25 & $43.9 \%$ & 21 & $84.0 \%$ & $\begin{array}{c}329.43 \\
( \pm 21.98) \\
\end{array}$ & $\begin{array}{c}460.25 \\
( \pm 122.21) \\
\end{array}$ & $\begin{array}{c}96.48 \\
( \pm 0.23) \\
\end{array}$ & $\begin{array}{c}91.75 \\
( \pm 0.13) \\
\end{array}$ \\
\hline Wingless & Yes & 54 & 30 & $55.6 \%$ & 15 & $50.0 \%$ & $\begin{array}{c}141.93 \\
( \pm 10.50) \\
\end{array}$ & $\begin{array}{c}382.07 \\
( \pm 34.17) \\
\end{array}$ & $\begin{array}{l}181.87 \\
( \pm 1.05) \\
\end{array}$ & $\begin{array}{l}437.33 \\
( \pm 1.31) \\
\end{array}$ \\
\hline Homo-specific & Yes & 67 & 36 & $53.7 \%$ & 22 & $61.1 \%$ & $\begin{array}{l}146.77 \\
( \pm 8.26) \\
\end{array}$ & $\begin{array}{r}351.93 \\
( \pm 30.53) \\
\end{array}$ & $\begin{array}{l}133.23 \\
( \pm 0.98) \\
\end{array}$ & $\begin{array}{l}172.43 \\
( \pm 0.80) \\
\end{array}$ \\
\hline Hetero-specific & Yes & 58 & 45 & $77.6 \%$ & 16 & $35.6 \%$ & $\begin{array}{c}84.13 \\
( \pm 6.94)\end{array}$ & $\begin{array}{c}276.72 \\
( \pm 12.94)\end{array}$ & $\begin{array}{l}163.44 \\
( \pm 2.19)\end{array}$ & $\begin{array}{l}347.07 \\
( \pm 1.38)\end{array}$ \\
\hline
\end{tabular}

Fed - states if females were blood-fed; $\mathrm{N}$ - number of trials in each condition; Copulation - number of trials where copulation occurred; Insemination - number of trials where copulation occurred and females were inseminated; Latency - average time until copulation; Duration - average time that the copulation lasted.

Latency and Duration were measured only in trials where copulation occurred. They were separated into trials where insemination occurred and those where it did not. Values in brackets are the standard error. 
Comparison of the 4 groups using a general linear model observed no significant differences in the number of copulations $(p=0.41)$ (Table 2$)$. However, when we compared the 4 unfed groups in relation to the insemination success there was a clear difference among them $(p<0.001)$ (Table 3$)$. The model for insemination rates (Table 3) showed not only a strong difference among groups but also an effect of Latency $(p=0.037)$ and copulation Duration $(p<0.001)$ on insemination success (Table 3$)$ with trials with shorter Latency and copulation Duration having a higher chance of success. Since the wingless group did not have any insemination, we could not perform a Post-Hoc pairwise comparison because of the large variance. In order to compare the 4 groups, we used Fisher's exact test (Supplemental Table 2). The result showed significant differences between winged and wingless trials and winged males versus hetero-specific song males (both $\mathrm{p}<0.001$ ). Comparison between homospecific versus either wingless or hetero-specific groups also showed significant differences $(p<0.001$ and $p=0.0014$ respectively). Finally, the comparison between winged males versus homo-specific and wingless versus heterospecific did not show any significant difference $(p=0.1296$ and $p=0.2178$ respectively) (Supplemental Table 2).

Table 2: Statistical results from the general linear model testing the copulation success among the 4 unfed groups. The result shows that the groups did not differ in copulation success.

\begin{tabular}{cccccc}
\hline & Df & Deviance & Resid. Df & Resid. Dev & $\operatorname{Pr}(>$ Chi) \\
\hline NULL & & & 414 & 574.04 & \\
\hline Group & 3 & 2.9015 & 411 & 571.14 & 0.4071 \\
\hline
\end{tabular}

NULL is the deviance of the null model used to test additional variables. 
Table 3: Statistical result from the general linear model testing the effect of treatments (Group), Latency and copulation duration (Duration) on insemination rate among the 4 unfed groups. All 3 variables affect insemination success.

\begin{tabular}{lccccc}
\hline & Df & Deviance & Resid. Df & $\begin{array}{c}\text { Resid. } \\
\text { Dev }\end{array}$ & $\operatorname{Pr}(>C h i)$ \\
\hline NULL & & & 218 & 225.14 & \\
\hline Group & 3 & 52.821 & 215 & 172.32 & $<0.0001^{* * *}$ \\
\hline Latency & 1 & 4.365 & 214 & 167.95 & $0.0367^{*}$ \\
\hline Duration & 1 & 11.109 & 213 & 156.84 & $0.0009^{* * *}$ \\
\hline
\end{tabular}

NULL is the deviance of the null model used to test additional variables.

Blood-feeding of females prior to the playback trials did not affect the percentage of copulation much except for trials with hetero-specific songs, which increased (Table 1, lower half). Our statistical test did not show an overall significant effect of blood feeding on copulation $(p=0.231)$ (Table 4 and Supplemental Table 2). However, blood feeding did increase insemination in all 4 fed groups with the control winged group reaching $84 \%$ success. There was a significant effect when comparing the overall insemination success against the unfed groups $(\mathrm{p}<0.001)$ (Table 5).

Table 4: Statistical result from the general linear model testing the effect of bloodfeeding on the number of copulations.

\begin{tabular}{cccccc} 
& Df & Deviance & Resid. Df & Resid. Dev & $\operatorname{Pr}(>$ Chi $)$ \\
\hline NULL & & & 650 & 897.12 & \\
\hline $\begin{array}{c}\text { Blood- } \\
\text { feeding }\end{array}$ & 1 & 1.4339 & 649 & 895.69 & 0.2311 \\
\hline
\end{tabular}

NULL is the deviance of the null model used to test additional variables. 
Table 5: Statistical result from the general linear model testing the effect of bloodfeeding on the insemination success.

\begin{tabular}{cccccc}
\hline & Df & Deviance & Resid. Df & Resid. Dev & $\operatorname{Pr}(>$ Chi $)$ \\
\hline NULL & & & 354 & 454.2 & \\
\hline $\begin{array}{c}\text { Blood- } \\
\text { feeding }\end{array}$ & 1 & 41.585 & 353 & 412.62 & $<0.0001^{* * *}$ \\
\hline
\end{tabular}

NULL is the deviance of the null model used to test additional variables.

Statistical analysis of the effects of the different group treatments, latency and copulation duration on the insemination success when females were blood fed showed a significant difference among Groups $(p<0.001)$ and an effect of both Latency and Duration of insemination ( $p<0.001$ and $p=0.013$ respectively) (Table 6). A pairwise comparison was again performed using Fisher's exact test. Winged males had significant differences when compared to wingless males and hetero-specific songs groups ( $p=0.011$ and $p=0.0001$ respectively) but not with the homo-specific group $(p=0.086)$. The difference between the homo specific and hetero specific groups were also significant $(p=0.027)$ showing a clear effect of song on insemination even with fed females. The other pairwise tests showed no significant results (Supplemental Table 3).

Table 6: General linear model testing the effect of treatments (Group), Latency and copulation duration (Duration) on insemination rate among the 4 fed groups. All 3 variables affect insemination success.

\begin{tabular}{cccccc}
\hline & Df & Deviance & Resid. Df Resid. & Dev & $\operatorname{Pr}(>$ Chi $)$ \\
\hline NULL & & & 135 & 187.48 & \\
\hline Group & 3 & 17.2160 & 132 & 170.26 & $<0.0001^{\star \star *}$ \\
\hline Latency & 1 & 11.9508 & 131 & 158.31 & $0.0006^{* * *}$ \\
\hline Duration & 1 & 6.1831 & 130 & 152.13 & $0.0129^{*}$ \\
\hline
\end{tabular}

NULL is the deviance of the null model used to test additional variables. 
Even though blood-feeding seemed to reduce female song discrimination there was still a consistent trend with winged males having the highest insemination success (84\%) and trials with homo-specific songs the second highest $(61.1 \%)$.

\section{Discussion:}

Despite the epidemiological importance of $L$. longipalpis, the sexual behaviour of this insect is poorly understood. Aside from the fact that males produce a pheromone that attracts both sexes and acoustic signals during copulation (Ward and Morton, 1991; Spiegel et al., 2005a; Watts et al., 2005; Araki et al., 2009; Spiegel et al., 2013; Vigoder et al., 2015; Souza et al., 2017) it is not really clear what affects reproductive success. In order to understand better this behaviour, we looked at the role of both male copulatory song and blood-feeding by females in the reproductive success of $L$. longipalpis

We observed a clear decline in insemination in trials where males had their wings removed thus preventing them from producing songs. The insemination success increased if the population specific songs (homo-specific) were played back to the couple but not if the wrong song (hetero-specific) was played (Figure 2, Table 1). This shows that the lack of reproductive success of wingless males was at least partly due to the lack of the appropriate acoustic signal and not because of some other effect (e.g. visual) caused by the wing as can happen in other species (Menezes et al., 2013). 
The results described here confirm the idea initially proposed when copulation songs were first described in L. longipalpis s.l., that songs affect insemination rate (de Souza et al., 2002; Souza et al., 2004; Vigoder et al., 2015), possibly due to cryptic female choice. This scenario also helps to understand why in some mating trials between Brazilian populations of $L$. longipalpis s.I. with different song types some copulation occurred in the laboratory, but no insemination. Hence, our study suggests that overall copulatory songs are likely to play an important role in fertilisation success and reproductive isolation. How song and other signals such as pheromonal variation may interact in influencing isolation would require further study manipulating both modes of signalling (Rybak et al., 2002).

In general, response to song varies among insect species with some recognizing only a conspecific song while others discriminate against heterospecific songs, so mating can occur in the absence of song (Isoherranen et al., 1999; Doi et al., 2001; Ritchie et al., 2005; Iglesias and Hasson, 2017). Since no insemination was observed in unfed females when no songs were played, females from Lapinha seem to be looking for the correct song before accepting or correctly processing sperm. An investigation on how females control insemination after copulation, depending on song stimulation, would be a very important follow-up to our study. Little is known about such effects in any species.

Blood-feeding was also shown to have an important influence in the reproductive success of $L$. longipalpis. When females were not blood-fed, even control trials with winged males had less than $50 \%$ insemination success, 
whereas blood-feeding females increased the insemination rate to $84 \%$ (Table $3)$.

Blood-fed females seemed to discriminate less against wingless males and against hetero-specific song, with a higher level of insemination being observed in these treatments. However, fed females with winged males (84\%) and homo-specific songs (61.1\%) still had the highest levels of success. The significant difference between the winged and hetero-specific song group (see Results; Supplemental Table 3) also suggests that there is still some level of discrimination even though females may be more ready to mate overall, presumably because reproductive opportunities are highest after blood-feeding and may be time-limited.

This decrease in female discrimination after they are blood-fed might have important evolutionary consequences. When we consider the sexual behaviour of $L$. longipalpis in nature, males display a lekking behaviour (Jarvis and Rutledge, 1992; Jones and Quinnell, 2002) where they arrive first at the host and then females arrive. Copulation likely happens during or immediately after blood-feeding on the host or nearby (Brazil and Brazil, 2018). Hence most copulation may involve recently fed females, potentially reducing sexual isolation and causing a higher level of introgression between closely related species making it more difficult for species to evolve complete sexual isolation. This may contribute to the introgression levels observed between species and populations of sand flies and amongst the high number of sister species in the L. longipalpis complex (Mazzoni et al., 2002; Bottecchia et al., 2004; Mazzoni et al., 2006; Mazzoni et al., 2008; Araki et al., 2009; Santos et al., 2013; Vigoder et al., 2015). 
In our study trials were performed 24 hours after blood-feeding. Since blood is essential for egg maturation and oviposition begins 3 days after the ingestion of blood (Brazil and Brazil, 2018), blood-feeding essentially starts a clock for successful reproduction. Virgin females also lay eggs if they ingest blood, so it is likely that as days pass female mate discrimination decreases in order to increase the chance of becoming inseminated, even accepting a less suitable mate. Because of the expected scenario in nature it is unlikely that females decrease discrimination during or immediately after feeding which would counter the effect of feeding on reducing sexual isolation. It would be important to measure the time scale of changes in female discrimination immediately after being blood-fed and 2 days after it in order to understand if discrimination does indeed lower only after some time has passed.

Aside from the association between time since blood-feeding and discrimination, other aspects of our study setup might also have inflated the insemination success in the hetero-specific group when females are blood-fed. First, our trials were performed in a no choice design which means females only had one male to choose from which given more opportunities might not have been the preferred male. In general, choice designs can reveal stronger mate preferences (Dougherty and Shuker, 2014). Second, both male and females used were from the same population. The reason for this was to isolate the effect of song in insemination however, males from diferent populations also vary in pheromones which are likely to also influence female choice (Brazil and Hamilton, 2002; Hamilton et al., 2005; Watts et al., 2005; Spiegel et al., 2016). Measuring the level of female discrimination when she is given the choice 
between a homo-specific and a hetero-specific male would also give fuller insight on the dynamics of L. longipalpis s.l. sexual behaviour.

Both Latency and Duration showed effects on insemination with trials where insemination occurred having a shorter time in both parameters in most cases (Table 1). In regard to Latency, the longer time in the no insemination trials suggests some sort of resistance from the female and that even if the males are able to overcome this, the mating is ultimately fruitless. The shorter copulation duration in the inseminated group indicates that once males clasp the females they invest in the copulation until insemination happens or the female breaks free, which she seems to try constantly (personal observation). The two exceptions to this pattern are where the hetero-specific unfed group and the winged blood-fed group had opposing values in Latency and Duration respectively. However, these results may be skewed by small sample sizes of results (2 or 4 in some comparisons) (Table 1$)$.

The present study focused on the Lapinha population. Considering that L. longipalpis s.I. is a species complex with different male copulatory songs, further studies are needed to see if the other populations/species of the complex behave and discriminate between copulatory courtship songs in a similar way. For instance, if the population used as the hetero-specific group here, Pancas, is also able to recognize and differentiate between homo-specific and hetero-specific song.

Our results demonstrate that both male copulatory courtship songs and female blood-feeding are important for reproductive success. As such these factors are important parts of the sexual behaviour of $L$. longipalpis. The fact that male copulatory courtship song has an important role in insemination 
success and that females can discriminate between homo-specific and heterospecific songs gives additional credence that populations with different song types constitute different species. 


\section{Acknowledgements}

We would like to thank Caroline Moraes for help with the collecting of sand-flies. The work was supported by CNPq (Science without Borders program) and CAPES.

This work is dedicated in memory of Alexandre Afranio Peixoto without whom this work would not be possible. 


\section{References:}

Araki, A.S., Ferreira, G.E., Mazzoni, C.J., Souza, N.A., Machado, R.C., Bruno, R.V., Peixoto, A.A., 2013. Multilocus analysis of divergence and introgression in sympatric and allopatric sibling species of the Lutzomyia longipalpis complex in Brazil. PLoS Negl Trop Dis 7, e2495.

Araki, A.S., Vigoder, F.M., Bauzer, L.G., Ferreira, G.E., Souza, N.A., Araujo, I.B., Hamilton, J.G., Brazil, R.P., Peixoto, A.A., 2009. Molecular and behavioral differentiation among Brazilian populations of Lutzomyia longipalpis (Diptera: Psychodidae: Phlebotominae). PLoS Negl Trop Dis 3, e365.

Bauzer, L.G., Gesto, J.S., Souza, N.A., Ward, R.D., Hamilton, J.G., Kyriacou, C.P., Peixoto, A.A., 2002a. Molecular divergence in the period gene between two putative sympatric species of the Lutzomyia longipalpis complex. Mol Biol Evol 19, 1624-1627.

Bauzer, L.G., Souza, N.A., Maingon, R.D., Peixoto, A.A., 2007. Lutzomyia longipalpis in Brazil: a complex or a single species? A mini-review. Mem Inst Oswaldo Cruz 102, 1-12.

Bauzer, L.G., Souza, N.A., Ward, R.D., Kyriacou, C.P., Peixoto, A.A., 2002b. The period gene and genetic differentiation between three Brazilian populations of Lutzomyia longipalpis. Insect Mol Biol 11, 315-323.

Bottecchia, M., Oliveira, S.G., Bauzer, L.G., Souza, N.A., Ward, R.D., Garner, K.J., Kyriacou, C.P., Peixoto, A.A., 2004. Genetic divergence in the cacophony IVS6 intron among five Brazilian populations of Lutzomyia longipalpis. J Mol Evol 58, 754-761.

Brazil, R.P., Brazil, B.G., 2018. Bionomy: Biology of Neotropical Phlebotomine Sand Flies. 299318.

Brazil, R.P., Caballero, N.N., Hamilton, J.G., 2009. Identification of the sex pheromone of Lutzomyia longipalpis (Lutz \& Neiva, 1912) (Diptera: Psychodidae) from Asuncion, Paraguay. Parasit Vectors 2, 51.

Brazil, R.P., Hamilton, J.G.C., 2002. Isolation and identification of 9-methylgermacrene-B as the putative sex pheromone of Lutzomyia cruzi (Mangabeira, 1938) (Diptera : Psychodidae).

Memorias Do Instituto Oswaldo Cruz 97, 435-436.

Casanova, C., Hamilton, J.G., Trigo, J.R., Costa, A.I., 2006. Identification of sex pheromones of Lutzomyia longipalpis (Lutz \& Neiva, 1912) populations from the state of Sao Paulo, Brazil. Mem Inst Oswaldo Cruz 101, 113-115.

Chen, A.L., Chen, C.C., Katoh, T., Katoh, T.K., Watada, M., Toda, M.J., Ritchie, M.G., Wen, S.Y., 2019. Evolution and diversity of the courtship repertoire in the Drosophila montium species group (Diptera: Drosophilidae). J Evol Biol 32, 1124-1140.

Clements, A.N., 2000. The biology of mosquitoes Vol. 1, Vol. 1. CABI, New York, NY [etc.]. de Souza, N.A., Ward, R.D., Hamilton, J.G., Kyriacou, C.P., Peixoto, A.A., 2002. Copulation songs in three siblings of Lutzomyia longipalpis (Diptera: Psychodidae). Trans R Soc Trop Med Hyg 96, 102-103.

Desutter-Grandcolas, L., Robillard, T., 2004. Acoustic evolution in crickets: need for phylogenetic study and a reappraisal of signal effectiveness. An Acad Bras Cienc 76, 301-315. Dieng, H., Satho, T., Abang, F., Wydiamala, E., Abu Kassim, N.F., Hashim, N.A., Zuharah, W.F., Noweg, G.T., 2019. Sex before or after blood feeding: Mating activities of Aedes aegypti males under conditions of different densities and female blood feeding opportunities. Journal of Asia-Pacific Entomology 22, 274-280.

Doi, M., Matsuda, M., Tomaru, M., Matsubayashi, H., Oguma, Y., 2001. A locus for female discrimination behavior causing sexual isolation in Drosophila. Proc Natl Acad Sci U S A 98, 6714-6719.

Dougherty, L., Shuker, D., 2014. The effect of experimental design on the measurement of mate choice: a meta-analysis. Behavioral Ecology 26.

Eberhard, W.G., 2001. Species-specific genitalic copulatory courtship in sepsid flies (Diptera, Sepsidae, Microsepsis) and theories of genitalic evolution. Evolution 55, 93-102. 
Edvardsson, M., Arnqvist, G., 2000. Copulatory courtship and cryptic female choice in red flour beetles Tribolium castaneum. Proc Biol Sci 267, 559-563.

Gorter, J.A., Jagadeesh, S., Gahr, C., Boonekamp, J.J., Levine, J.D., Billeter, J.-C., 2016. The nutritional and hedonic value of food modulate sexual receptivity in Drosophila melanogaster females. Scientific reports 6, 19441-19441.

Grosjean, Y., Rytz, R., Farine, J.P., Abuin, L., Cortot, J., Jefferis, G.S., Benton, R., 2011. An olfactory receptor for food-derived odours promotes male courtship in Drosophila. Nature 478, 236-240.

Hamilton, J.G., Dawson, G.W., Pickett, J.A., 1996a. 9-Methylgermacrene-B; proposed structure for novel homosesquiterpene from the sex pheromone glands ofLutzomyia longipalpis (Diptera: Psychodidae) from Lapinha, Brazil. J Chem Ecol 22, 1477-1491. Hamilton, J.G., Maingon, R.D., Alexander, B., Ward, R.D., Brazil, R.P., 2005. Analysis of the sex pheromone extract of individual male Lutzomyia longipalpis sandflies from six regions in Brazil. Med Vet Entomol 19, 480-488.

Hamilton, J.G.C., Dawson, G.W., Pickett, J.A., 1996b. 3-Methyl- $\alpha$-himachalene: Proposed structure for novel homosesquiterpene sex pheromone ofLutzomyia longipalpis (diptera: Psychodidae) from Jacobina, Brazil. Journal of Chemical Ecology 22, 2331-2340.

Hamilton, J.G.C., Dougherty, M.J., Ward, R.D., 1994. Sex-Pheromone Activity in a SingleComponent of Tergal Gland Extract of Lutzomyia-Longipalpis (Diptera, Psychodidae) from Jacobina, Northeastern Brazil. Journal of Chemical Ecology 20, 141-151.

Hoikkala, A., Aspi, J., Suvanto, L., 1998. Male courtship song frequency as an indicator of male genetic quality in an insect species, Drosophila montana. P Roy Soc B-Biol Sci 265, 503-508. Hoy, R.R., Hoikkala, A., Kaneshiro, K., 1988. Hawaiian courtship songs: evolutionary innovation in communication signals of Drosophila. Science 240, 217-219.

Hunt, J., Sakaluk, S.K., 2014. Mate choice, The Evolution of Insect Mating Systems. Oxford University Press, Oxford, pp. 129-158.

Huttunen, S., Aspi, J., Schlotterer, C., Routtu, J., Hoikkala, A., 2008. Variation in male courtship song traits in Drosophila virilis: the effects of selection and drift on song divergence at the intraspecific level. Behav Genet 38, 82-92.

Iglesias, P.P., Hasson, E., 2017. The role of courtship song in female mate choice in South American Cactophilic Drosophila. PLoS One 12, e0176119.

Isoherranen, E., Aspi, J., Hoikkala, A., 1999. Variation and consistency of female preferences for simulated courtship songs in Drosophila virilis. Anim Behav 57, 619-625.

Jarvis, E.K., Rutledge, L.C., 1992. Laboratory observations on mating and leklike aggregations in Lutzomyia longipalpis (Diptera: Psychodidae). J Med Entomol 29, 171-177.

Johansson, B.G., Jones, T.M., 2007. The role of chemical communication in mate choice.

Biological Reviews 82, 265-289.

Jones, T.M., Quinnell, R.J., 2002. Testing predictions for the evolution of lekking in the sandfly, Lutzomyia longipalpis. Animal Behaviour 63, 605-612.

Kraaijeveld, K., Kraaijeveld-Smit, F.J., Maan, M.E., 2011. Sexual selection and speciation: the comparative evidence revisited. Biol Rev Camb Philos Soc 86, 367-377.

Lehane, M., 2005. The Biology of Blood-Sucking Insects. Cambridge: Cambridge University Press.

Lewis, S.M., Vahed, K., Koene, J.M., Engqvist, L., Bussiere, L.F., Perry, J.C., Gwynne, D., Lehmann, G.U., 2014. Emerging issues in the evolution of animal nuptial gifts. Biol Lett 10. Li, D., Oh, J., Kralj-Fiser, S., Kuntner, M., 2012. Remote copulation: male adaptation to female cannibalism. Biol Lett 8, 512-515.

Lins, R.M., Souza, N.A., Peixoto, A.A., 2008. Genetic divergence between two sympatric species of the Lutzomyia longipalpis complex in the paralytic gene, a locus associated with insecticide resistance and lovesong production. Mem Inst Oswaldo Cruz 103, 736-740.

Maan, M.E., Seehausen, O., 2011. Ecology, sexual selection and speciation. Ecol Lett 14, 591602. 
Mazzoni, C.J., Araki, A.S., Ferreira, G.E., Azevedo, R.V., Barbujani, G., Peixoto, A.A., 2008. Multilocus analysis of introgression between two sand fly vectors of leishmaniasis. BMC Evol Biol 8, 141.

Mazzoni, C.J., Gomes, C.A., Souza, N.A., de Queiroz, R.G., Justiniano, S.C., Ward, R.D., Kyriacou, C.P., Peixoto, A.A., 2002. Molecular evolution of the period gene in sandflies. J Mol Evol 55, 553-562.

Mazzoni, C.J., Souza, N.A., Andrade-Coelho, C., Kyriacou, C.P., Peixoto, A.A., 2006. Molecular polymorphism, differentiation and introgression in the period gene between Lutzomyia intermedia and Lutzomyia whitmani. BMC Evol Biol 6, 85.

Menezes, B.F., Vigoder, F.M., Peixoto, A.A., Varaldi, J., Bitner-Mathé, B.C., 2013. The influence of male wing shape on mating success in Drosophila melanogaster. Animal behaviour 2013 v. 85 no.6, pp. 1217-1223.

Peretti, A.V., Eberhard, W.G., 2010. Cryptic female choice via sperm dumping favours male copulatory courtship in a spider. J Evol Biol 23, 271-281.

Rangel, E.F., Shaw, J.J., 2018. Brazilian Sand Flies

Ready, P.D., Vigoder, F.M., Rangel, E.F., 2018. Molecular and Biochemical Markers for Investigating the Vectorial Roles of Brazilian Sand Flies. 213-250.

Ritchie, M.G., 2007. Sexual Selection and Speciation. Annual Review of Ecology, Evolution, and Systematics 38, 79-102.

Ritchie, M.G., Saarikettu, M., Hoikkala, A., 2005. Variation, but no covariance, in female preference functions and male song in a natural population of Drosophila montana. Animal Behaviour 70, 849-854.

Rybak, F., Sureau, G., Aubin, T., 2002. Functional coupling of acoustic and chemical signals in the courtship behaviour of the male Drosophila melanogaster. Proc Biol Sci 269, 695-701. Santos, M.F., Ribolla, P.E., Alonso, D.P., Andrade-Filho, J.D., Casaril, A.E., Ferreira, A.M., Fernandes, C.E., Brazil, R.P., Oliveira, A.G., 2013. Genetic structure of Lutzomyia longipalpis populations in Mato Grosso Do Sul, Brazil, based on microsatellite markers. PLoS One 8, e74268.

Servedio, M.R., Boughman, J.W., 2017. The Role of Sexual Selection in Local Adaptation and Speciation. Annual Review of Ecology, Evolution, and Systematics 48, 85-109.

Souza, N.A., Andrade-Coelho, C.A., Vigoder, F.M., Ward, R.D., Peixoto, A.A., 2008.

Reproductive isolation between sympatric and allopatric Brazilian populations of Lutzomyia longipalpis s.I. (Diptera: Psychodidae). Mem Inst Oswaldo Cruz 103, 216-219.

Souza, N.A., Brazil, R.P., Araki, A.S., 2017. The current status of the Lutzomyia longipalpis (Diptera: Psychodidae: Phlebotominae) species complex. Mem Inst Oswaldo Cruz 112, 161174.

Souza, N.A., Vigoder, F.M., Araki, A.S., Ward, R.D., Kyriacou, C.P., Peixoto, A.A., 2004. Analysis of the copulatory courtship songs of Lutzomyia longipalpis in six populations from Brazil. J Med Entomol 41, 906-913.

Spiegel, C.N., Bretas, J.A., Peixoto, A.A., Vigoder, F.M., Bruno, R.V., Soares, M.J., 2013. Fine structure of the male reproductive system and reproductive behavior of Lutzomyia longipalpis sandflies (Diptera: Psychodidae: Phlebotominae). PLoS One 8, e74898.

Spiegel, C.N., Dias, D.B., Araki, A.S., Hamilton, J.G., Brazil, R.P., Jones, T.M., 2016. The Lutzomyia longipalpis complex: a brief natural history of aggregation-sex pheromone communication. Parasit Vectors 9, 580.

Spiegel, C.N., Jeanbourquin, P., Guerin, P.M., Hooper, A.M., Claude, S., Tabacchi, R., Sano, S., Mori, K., 2005a. (1S,3S,7R)-3-methyl-alpha-himachalene from the male sandfly Lutzomyia longipalpis (Diptera: Psychodidae) induces neurophysiological responses and attracts both males and females. J Insect Physiol 51, 1366-1375.

Spiegel, C.N., Oliveira, S.M., Brazil, R.P., Soares, M.J., 2005b. Structure and distribution of sensilla on maxillary palps and labella of Lutzomyia longipalpis (Diptera: Psychodidae) sand flies. Microsc Res Tech 66, 321-330. 
Takken, W., Costantini, C., Dolo, G., Hassanali, A., Sagnon, N.F., Osir, E., 2006. Mosquito mating behaviour. 183-188.

Tishechkin, D.Y., Vedenina, V.Y., 2016. Acoustic signals in insects: A reproductive barrier and a taxonomic character. Entomological Review 96, 1127-1164.

Vigoder, F.M., Araki, A.S., Bauzer, L.G., Souza, N.A., Brazil, R.P., Peixoto, A.A., 2010. Lovesongs and period gene polymorphisms indicate Lutzomyia cruzi (Mangabeira, 1938) as a sibling species of the Lutzomyia longipalpis (Lutz and Neiva, 1912) complex. Infect Genet Evol 10, 734739.

Vigoder, F.M., Ritchie, M.G., Gibson, G., Peixoto, A.A., 2013. Acoustic communication in insect disease vectors. Mem Inst Oswaldo Cruz 108 Suppl 1, 26-33.

Vigoder, F.M., Souza, N.A., Brazil, R.P., Bruno, R.V., Costa, P.L., Ritchie, M.G., Klaczko, L.B., Peixoto, A.A., 2015. Phenotypic differentiation in love song traits among sibling species of the Lutzomyia longipalpis complex in Brazil. Parasit Vectors 8, 290.

Ward, R., Phillips, A., Burnet, B., 1986. Genetic isolating mechanisms between different forms of the sandfly Lutzomyia longipalpis (Diptera: Psychodidae). Ann Ist Super Sanita 22, 69-72.

Ward, R.D., Morton, I.E., 1991. Pheromones in mate choice and sexual isolation between siblings of Lutzomyia longipalpis (Diptera:Psychodidae). Parassitologia 33 Suppl, 527-533.

Ward, R.D., Phillips, A., Burnet, B., Marcondes, C.B., 1988. The Lutzomyia longipalpis complex: reproduction and distribution. , in: Service, M.W. (Ed.), Biosystematics of haematophagous insects. Clarendon Press, Oxford Systematics Association Special, pp. 257-269.

Watts, P.C., Hamilton, J.G., Ward, R.D., Noyes, H.A., Souza, N.A., Kemp, S.J., Feliciangeli, M.D., Brazil, R., Maingon, R.D., 2005. Male sex pheromones and the phylogeographic structure of the Lutzomyia longipalpis species complex (Diptera: Psychodidae) from Brazil and Venezuela. Am J Trop Med Hyg 73, 734-743. 


\section{Figure Legends:}

Figure 1: Sample of the natural and synthetic copulatory courtship songs of $L$. longipalpis s.I. males. A - Natural song from the Lapinha population which has a P2 Pulse-type song. B - Synthetic Pulse-type song, used as the homo-specific song. The Lapinha P2 song was used as template (Vigoder et al, 2015). C Synthetic Burst-type song, used as the hetero-specific song. Song from Pancas was used as template (Vigoder et al, 2015).

Figure 2: Insemination success in the treatment groups. In blue are trials when females were not blood-fed and in red when females were blood-fed. Error bars are Confidence Intervals for a population proportion. Lines on top with asterisks mark the significant pairwise comparisons. Blue lines refer to comparison in the unfed treatment and in red the fed treatment. 


\section{Supplemental material:}

Supplemental material 1: Sample of one train of a P2 Pulse-type song produced by males from Lapinha (MG).

Supplemental material 2: Sample of one train of a Burst-type song produced by males from Pancas (ES).

Supplemental material 3: Synthetic song that was used to emulate the P2 Pulse-type song. This song was the one used in the homo-specific group.

Supplemental material 4: Synthetic song that was used to emulate the Bursttype song. This song was the one used in the hetero-specific group. 


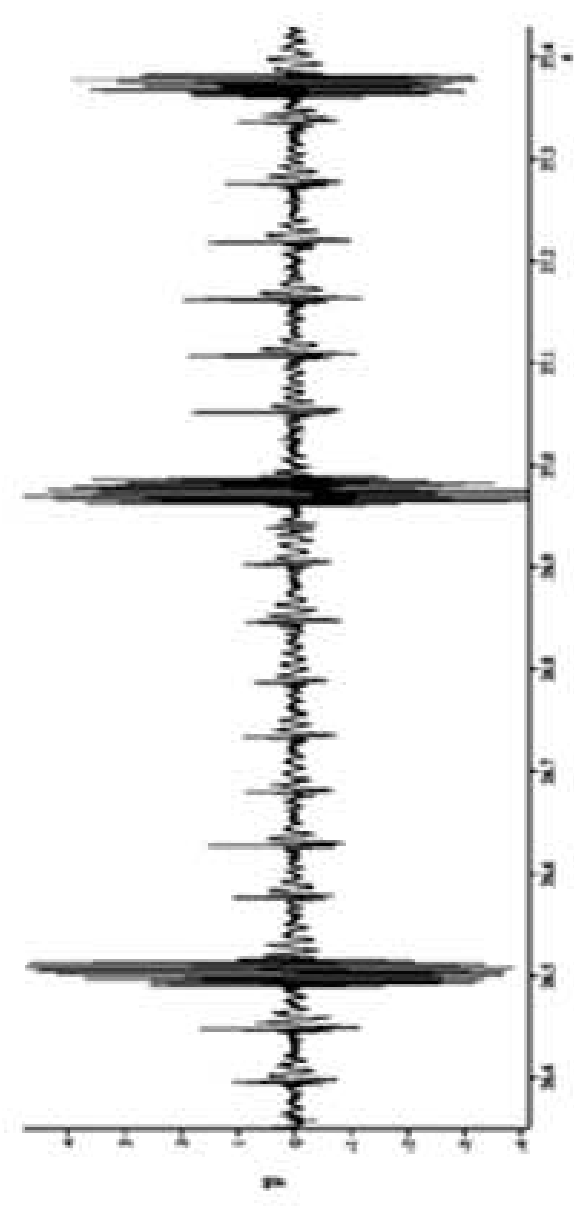

$\varangle$

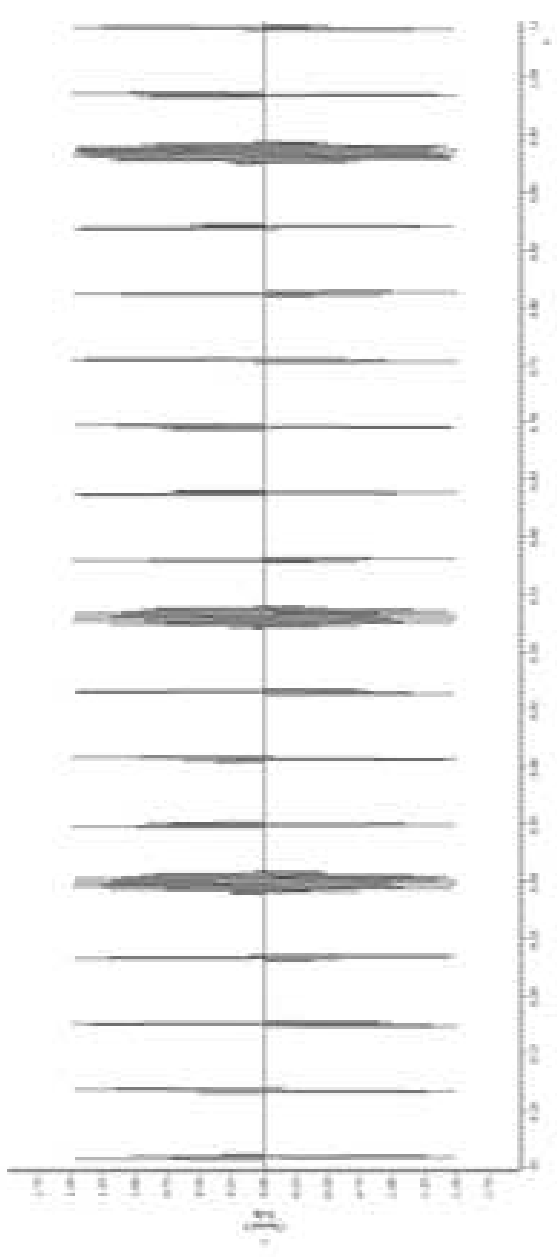

$\infty$
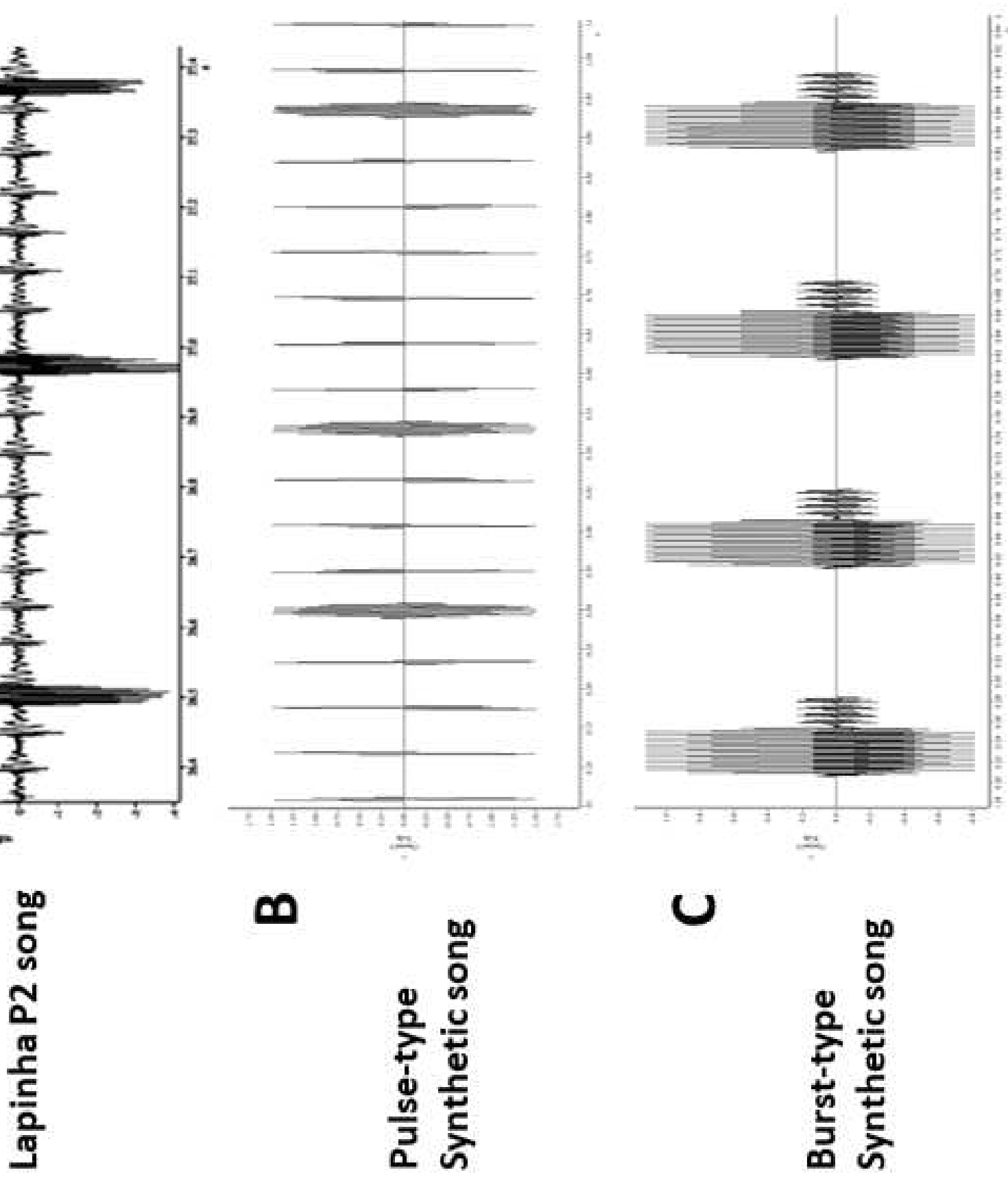
总路

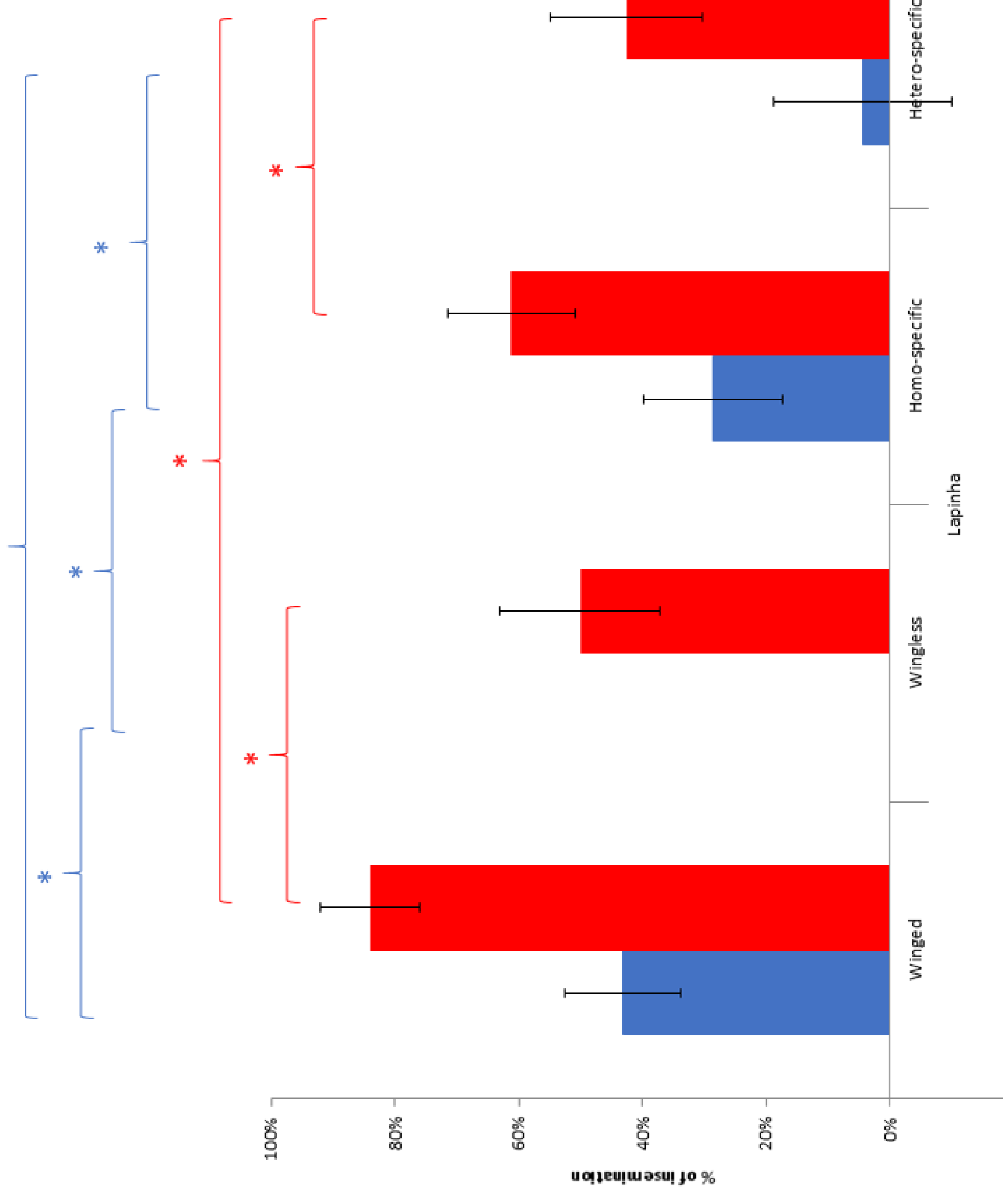


Supplemental Table 1: List of the Brazilian populations of L. longipalpis s.l. where it is known the male copulatory courtship song. The table shows the population, Brazilian State where it is located and the song type. The 1S and 2S next to the name of some populations refers to the number of tergal spot pairs in the male where the spots seem to mark two sympatric species. Data from Araki et al, 2009 and Vigoder et al, 2015.

\begin{tabular}{ccc}
\hline Population & State & Song-type \\
\hline Jacobina & Bahia & Pulse 1 \\
\hline Lapinha & Minas Gerais & Pulse 2 \\
\hline Sobral 1S & Ceará & Pulse 3 \\
\hline Teresina & Ceará & Pulse 3 \\
\hline Jaiba 1S & Minas Gerais & Pulse 4 \\
\hline Pirenópolis & Goiás & Pulse 4 \\
\hline Palmas 1S & Tocantins & Pulse 4 \\
\hline Lassance & Minas Gerais & Pulse 4 \\
\hline Estrela 1S & Alagoas & Pulse 5 \\
\hline Natal & Rio Grande do Norte & Burst \\
\hline Marajó & Pará & Burst \\
\hline Sobral 2S & Ceará & Burst \\
\hline Estrela 2S & Alagoas & Burst \\
\hline Jaíba 2S & Minas Gerais & Burst \\
\hline Pancas & Espírito Santo & Burst \\
\hline Nova Porteirinha & Minas Gerais & Burst \\
\hline Barcarena & Pará & Burst \\
\hline Itamaracá & Pernambuco & Burst \\
\hline Passira & Pernambuco & Burst \\
\hline Camará & Pará & Burst \\
\hline Palmas 2S & Tocantins & Burst \\
\hline Afonso Cláudio & Espírito Santo & Burst \\
\hline Aracajú & Sergipe & Burst \\
\hline Cametá & Pará & Burst \\
\hline Ipanema & Minas Gerais & Burst \\
\hline Mesquita & Rio de Janeiro & Mix \\
\hline & &
\end{tabular}


Supplemental Table 2: Pairwise comparison using Fisher's exact test. The comparison was performed using the 4 unfed groups and shows the differences in the insemination success.

\begin{tabular}{|c|c|c|c|c|}
\hline & Winged & Wingless & Homosp & Heterosp \\
\hline Winged & & $\mathbf{p}<\mathbf{0 . 0 0 0 1}$ & $\mathbf{p}=0.1296$ & $\mathbf{p}<\mathbf{0 . 0 0 0 1}$ \\
\hline Wingless & & & $\mathbf{p}<\mathbf{0 . 0 0 0 1}$ & $\mathrm{p}=0.2178$ \\
\hline Homosp & & & & $\mathbf{p}=\mathbf{0 . 0 0 1 4}$ \\
\hline Heterosp & & & & \\
\hline
\end{tabular}

Winged $=$ trials with unmodified males; Wingless = trials with males without wings; Homosp $=$ trials with homospecific song played; Heterosp $=$ trials with heterospecific song played 
Supplementary Table 3: Pairwise comparison using Fisher's exact test. The comparison was performed using the 4 fed groups and shows the differences in the insemination success.

\begin{tabular}{|c|c|c|c|c|}
\hline & Winged & Wingless & Homosp & Heterosp \\
\hline Winged & & $\mathbf{p}=\mathbf{0 . 0 1 1}$ & $\mathrm{p}=0.086$ & $\mathbf{p}=\mathbf{0 . 0 0 0 1}$ \\
\hline Wingless & & & $\mathrm{p}=0.457$ & $\mathrm{p}=0.239$ \\
\hline Homosp & & & & $\mathbf{p}=\mathbf{0 . 0 2 7}$ \\
\hline Heterosp & & & & \\
\hline
\end{tabular}

Winged $=$ trials with unmodified males; Wingless = trials with males without wings; Homosp $=$ trials with homospecific song played; Heterosp $=$ trials with heterospecific song played 